\title{
A clinical study on the expression of PTEN in renal cell carcinoma in children
}

\author{
HONG LU, YUXIA TAN and LIPING CHEN \\ Department of Pediatrics, Zibo Maternal and Child Health Care Hospital, Zibo, Shandong 255029, P.R. China
}

Received September 27, 2017; Accepted September 27, 2018

DOI: $10.3892 / \mathrm{ol} .2018 .9571$

\begin{abstract}
The expression pattern of tumor suppressor gene phosphatase and tensin homolog deleted on chromosome ten (PTEN) and phosphatase and tensin homolog deleted on chromosome ten/phosphatidylinositol3-kinase/protein kinase B (PTEN/PI3K/AKT) cell signaling pathway in renal cell carcinoma (RCC) were investigated in children. A total of 5 cases of RCC (observation group) in children and 10 cases of benign kidney tumor (control group) diagnosed by pathological examinations were included to obtain tumor samples. Expression of PTEN mRNA was detected by reverse transcription-quantitative polymerase chain reaction (RT-qPCR). The protein expression of PTEN, PI3K and AKT was detected by western blotting; relationships between the expression level of PTEN mRNA and the clinical features of RCC were analyzed. It turned out that expression level of PTEN mRNA in the observation group was significantly lower than that in the control group. The protein expression levels of PTEN, PI3K and AKT were significantly lower in the observation group than in the control group $(\mathrm{P}<0.05)$. The expression level of PTEN mRNA decreased with the increased clinical stage of RCC $(\mathrm{P}<0.05)$, and was not related to sex, age and maximum tumor diameter $(\mathrm{P}>0.05)$. The results showed that downregulation of the tumor suppressor gene PTEN expression and the inhibition of PTEN/PI3K/AKT cell signaling pathway may be involved in the occurrence and development of RCC in children.
\end{abstract}

\section{Introduction}

The incidence of children's renal cell carcinoma (RCC) is low. This disease affects 2.2 in 100,000 individuals, and the age of onset is usually older than 5 years, but the prognosis is poor (1). Malignant kidney tumor in children is mainly nephroblastoma (2). Some studies (3) have pointed out that chromosome

Correspondence to: Dr Liping Chen, Department of Pediatrics, Zibo Maternal and Child Health Care Hospital, 11 Xingyuan East Road, Zibo, Shandong 255029, P.R. China

E-mail: cmkz90@163.com

Key words: PTEN, PTEN/PI3K/AKT cell signaling pathway, renal cell carcinoma in children
Xp11.2 translocation induced-fracture of transcription plays an important role in the development of RCC in children, suggesting that the occurrence of RCC in children may be related to genetic variations. Recent studies shown that tumor suppressor gene phosphatase and tensin homolog deletions on chromosome ten (PTEN) is closely related to the occurrence and development of multiple malignant tumors such as glioma (4), breast cancer (5), liver cancer (6), colon cancer (7) and prostate cancer (8), and plays an important role in the inhibition of cell proliferation, cell migration and cell adhesion (9), and induction of apoptosis (10), embryonic development (11) and angiogenesis (12). PI3K/AKT is an important downstream target of PTEN, and PTEN/PI3K/AKT cell signaling pathway may play an important role in the occurrence and development of multiple tumors. This study investigated the expression pattern of PTEN and PTEN/PI3K/AKT cell signaling pathway in RCC in children.

\section{Patients and methods}

Patient information. A total of 5 cases of RCC (observation group) in children and 10 cases of benign renal tumors (control group) diagnosed by pathological examinations were selected in Zibo Maternal and Child Health Care Hospital (Zibo, China) from June 2013 to June 2017. There were 3 boys and 2 girls in the observation group, with an age range from 5 to 10 years, with an average age of $7.5 \pm 2.3$ years. For clinical tumor TNM staging, there were 2 cases of Stage I-II and 3 cases of Stage III-IV. The maximum tumor diameter ranged from 1.3 to $4.3 \mathrm{~cm}$, with an average maximum tumor diameter of $2.7 \pm 1.5 \mathrm{~cm}$. There was no significant difference in sex, age and maximum tumor diameter between the two groups $(\mathrm{P}>0.05)$.

The study was approved by the Ethics Committee of Zibo Maternal and Child Health Care Hospital and the parents/ guardians of the children signed the informed consent.

Research methods. Tumor specimens were obtained by surgery, and preserved in $-70^{\circ} \mathrm{C}$ liquid nitrogen. The expression of PTEN mRNA in tumor tissue was detected by reverse transcription-quantitative polymerase chain reaction (RT-qPCR). The protein expression of PTEN, PI3K and AKT in tumor tissues was detected by western blotting. The relationship between the expression level of PTEN mRNA and the clinical features of RCC was analyzed. The procedure was repeated 3 times. 


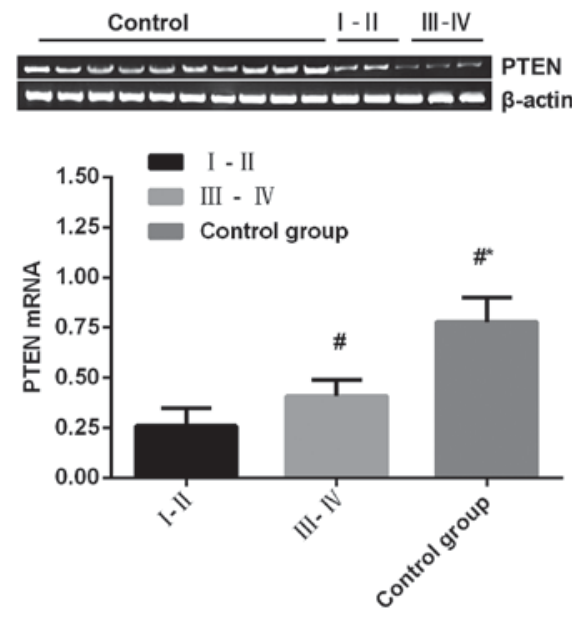

Figure 1. The expression level of PTEN mRNA is measured by RT-qPCR. $\mathrm{n}=3,{ }^{\#} \mathrm{P}<0.05$, compared with stageI-II. ${ }^{*} \mathrm{P}<0.05$, compared with stage III-IV.

RT-qPCR method.Total RNA was extracted using TRIzol reagent (Beijing Zhongshan Goldenbridge Co., Ltd., Beijing, China) according to the manufacturer's protocol. RNA quality was checked by $1.5 \%$ agarose gel electrophoresis. SYBR-Green Irealtime fluorescence PCR kit were used (Thermo Fisher Scientific, Inc. Waltham, MA, USA). Total RNA ( $2 \mu \mathrm{g})$ was used in reverse transcription as template to synthesize cDNA according to the manufacturer's protocol of the reverse transcription kit (SigmaAldrich; Merck KGaA, Darmstadt, Germany). Then, $2 \mu \mathrm{l}$ cDNA was used in PCR reaction. Primers were synthesized by Sangon Biotech (Shanghai) Co., Ltd., Shanghai, China. Primers used in PCR reactions were: 5'-TTGATTGCATCTCCATCTCCT-3' (forward) and 5'-AAGAGATGGCCACGGCTGCT-3' (reverse) for $\beta$-actin, and length of PCR product was $421 \mathrm{bp}$; primer: 5'-TTGATTGCATCTCCATCTCCT-3' (forward) and 5'-TTCGCTTTCTCTGAGCATTCT-3' (reverse) for PTEN, and length of PCR product was $249 \mathrm{bp}$. Reaction conditions were: $94^{\circ} \mathrm{C}$ for $2 \mathrm{~min}$, followed by 30 cycles of $94^{\circ} \mathrm{C}$ for $30 \mathrm{sec}$, $56^{\circ} \mathrm{C}$ for $30 \mathrm{sec}$ and $72^{\circ} \mathrm{C}$ for $1 \mathrm{~min}$. PCR product $(6 \mu \mathrm{l})$ was subjected to $1.5 \%$ agarose gel electrophoresis, and gray value quantification was carried out with ultraviolet imaging system (Olympus, Tokyo, Japan). The data was quantified using the $2^{-\Delta \Delta C q}$ method (13).

Western blotting. Total protein was extracted from tumor tissue, and then protein samples were subjected to $10 \%$ SDS-PAGE gel electrophoresis. The PVDF membranes were blocked and incubated with mouse anti-human monoclonal PTEN, PI3K and AKT protein primary antibodies (1:2,000; cat. nos. P3487, SAB5300225 and SAB4100001; Sigma-Aldrich; Merck $\mathrm{KGaA}$ ), overnight at $4^{\circ} \mathrm{C}$. After washing with phosphatebuffered saline (PBS), membranes were incubated with rabbit anti-mouse polyclonal anti-immunoglobulin G (anti-IgG) secondary antibody (1:500; cat. no. SAB3701023; Sigma-Aldrich; Merck KGaA) at $37^{\circ} \mathrm{C}$ for $4 \mathrm{~h}$. Signal detection was performed by ECL (Jiangsu Beyotime Biotechnology Co., Ltd., Jiangsu, China) method, and signals were analyzed using image analysis software (Invitrogen; Thermo Fisher Scientific, Inc., Waltham, MA, USA) to calculate the gray values of each group, and expression of each protein was normalized to endogenous control $\beta$-actin.

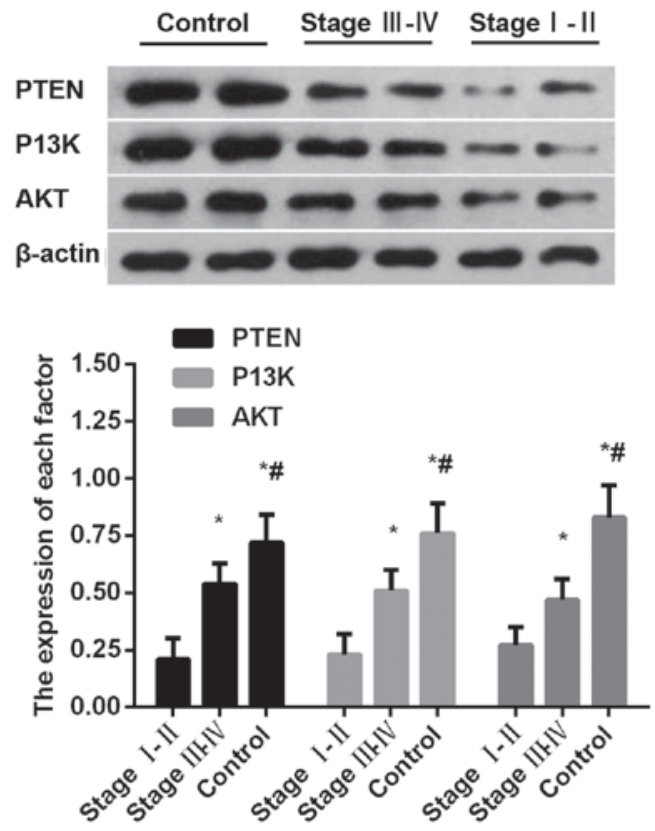

Figure 2. Protein expression levels of PTEN, PI3K and AKT measured by western blotting. $\mathrm{n}=3,{ }^{\#} \mathrm{P}<0.05$, compared with stageI-II. ${ }^{*} \mathrm{P}<0.05$, compared with stage III-IV.

Statistical analysis. Statistical Product and Service Solutions (SPSS Inc., Chicago, IL, USA) 20.0 software was used for statistical analysis. Measurement data were expressed as mean \pm standard deviation, and independent sample t-test (Student's t-test) was used for comparisons among groups. Enumeration data were expressed as cases or (\%), and $\chi^{2}$ test was used for comparisons among groups. $\mathrm{P}<0.05$ indicated that the difference was statistically significant.

\section{Results}

Comparison of PTEN mRNA expression level among groups. The expression level of PTEN mRNA in the observation group was significantly lower than that in control group $(\mathrm{P}<0.05)$ (Fig. 1).

Comparison of protein expression levels of PTEN, PI3K and AKT among groups. Protein expression levels of PTEN, PI3K and AKT in observation group were significantly lower than those in control group $(\mathrm{P}<0.05)$ (Fig. 2).

Relationship between expression levels of PTEN $m R N A$ and clinical features of RCC in the tissue. Expression levels of PTEN mRNA decreased with the increased clinical stages of RCC $(P=0.003)$, and were not related to sex $(P=0.865)$, age $(\mathrm{P}=0.765)$ and maximum tumor diameter $(\mathrm{P}=0.649)$ (Table $\mathrm{I})$.

\section{Discussion}

Although clinical incidence of RCC in children is relatively low, prognosis is very poor. Pathogenesis of RCC in children is still unclear. Some studies have shown that occurrence of RCC is closely correlated with genetic variation (14). In this study, expression levels of PTEN mRNA in observation group were significantly lower than those in control group, protein 
Table I. The relationship between expression level of PTEN mRNA and clinical features of RCC in the tissues.

\begin{tabular}{lcccc}
\hline Clinical features & Cases & PTEN mRNA & t value & P-value \\
\hline Clinical stages & & & 10.326 & $<0.001$ \\
I-II & 2 & $0.4326 \pm 0.1322$ & & \\
III-IV & 3 & $0.2053 \pm 0.0968$ & & \\
Age (years) & & & 0.152 & 0.865 \\
$\quad<7.5$ & 2 & $0.2465 \pm 0.0865$ & & \\
$\geq 7.5$ & 3 & $0.2596 \pm 0.0759$ & & \\
Sex & & & 0.263 & 0.765 \\
$\quad$ Boys & 3 & $0.2365 \pm 0.0965$ & & \\
Girls & 2 & $0.2642 \pm 0.0825$ & & \\
Max tumor & & & 0.325 & 0.649 \\
diameters (cm) & & & & \\
$<2.9$ & 3 & $0.2323 \pm 0.0854$ & & \\
$\geq 2.9$ & 2 & $0.2706 \pm 0.0926$ & & \\
\hline
\end{tabular}

expression levels of PTEN, PI3K and AKT were significantly lower in observation group than those in control group expression level of PTEN mRNA decreased with the increased clinical stages of RCC, and was not related to the sex, age and maximum tumor diameter. Therefore, it is speculated that reduced expression level of tumor suppressor gene PTEN and the inhibition of PTEN/PI3K/AKT cell signaling pathway was very likely to be involved in the occurrence and development of RCC in children.

PTEN is located on chromosome 10q23, and its reduced expression level is related to tumorigenesis (15). In vitro experiments showed that PTEN could rapidly block the cell cycle arrest in G1 phase and induce cell apoptosis (16). PTEN can also inhibit the expression of PIP3 and block PI3K/AKT signaling pathway (17), alter cell morphology, downregulate actin filament protein expression, and participate in tumor cell migration and local adhesion (18). The multiple biological activities of PTEN were achieved through focal adhesion kinase (FAK), PIP3, mitogen activated protein kinase (MAPK), cyclin and other signaling pathways. Zhang et al (19) have shown that PTEN can dephosphorylate FAK, downregulate the expression of downstream target gene p130CAS of FAK, thereby inhibiting tumor growth, infiltration and metastasis. PTEN can also affect the activity of FAK then inhibiting the activation of PI3K/AKT pathway. PIP3 is transformed into PIP2 by dephosphorylation, thereby blocking PI3K/PKB/AKT pathway, and regulating cell proliferation and apoptosis (20). PIP3 is an important reaction substrate of PTEN, so expression of PIP3 protein is closely related to active state of lipid phosphatase (21). Some studies have pointed out that (22) PTEN can inhibit the biological activity of extracellular regulated protein kinases (ERK) in MAPK pathway. PTEN can regulate the expression of cyclin-dependent protein kinase (CDK). Overexpression of PTEN can dephosphorylate substrate retinoblastoma protein $(\mathrm{pRb})$, and moreover combine with transcription factor E2F to significantly reduce cell proliferative potential (23). Some studies have shown that $(17,24)$ PTEN/PI3K/AKT cell signaling pathway can activate kinase system, and then regulates expression of multiple cytokines such as VEGF and hypoxia inducible factor $1 \alpha$ (HIF-1 $\alpha)$, so as to participate in tumorigenesis. Activation of AKT depends on upstream PI3K. PI3K can regulate cell metabolism, cell proliferation and cell apoptosis. AKT is the central downstream effector of PI3K. The activated AKT can phosphorylate multiple proteins to participate in cell growth, cell development and vascular regulation. AKT activity is closely related to neuronal cell death. AKT promotes cell apoptosis through the opposite effect of PTEN. AKT activity may decrease with time. The long-term specimen preservation may affect experimental results.

Regarding AKT phosphorylation, the occurrence and development of renal cell carcinoma is related to various growth factors such as platelet-derived growth factor (PDGF) and epidermal growth factor (EGF), while AKT phosphorylation is mainly regulated by P13K-AKT. AKT is translocated into the plasma membrane and then binds to $\operatorname{Ptd} \operatorname{Ins}(3,4,5) \mathrm{P} 3$ or PtdIns(3,4)P2 generated by P13K activation to be phosphorylated, whereas PtdIns(3,4,5)P3 and PtdIns(3,4) P2 are active factors and can easily react with various cellular factors. In the course of the preservation of the specimens in this experiment, it was not ruled out that the phosphorylation ability of AKT varied due to the activation of the two factors. Thus, we did not focus on the phosphorylated AKT, we will work on this problem in the following study.

RT-qPCR was performed due to the limited resources, which can cause errors in our data. Incidence of renal cell carcinoma in children is not high, and only 8 patients were admitted by our hospital in past 3 years. Among those 8 cases, 3 patients were transferred to other hospitals during treatment, so we cannot include them in this study; therefore, only 5 tumor samples were utilized in this study, which is a limitation. Pediatric renal cell carcinoma is an incurable disease that is extremely rare in clinical practice. Studies on the pathogenesis, diagnosis, and treatment methods of this disease are also rare. PTEN plays pivotal roles in this disease and may serve as a potential target for the treatment. The small sample size may affect the reliability of our data. We will try to include more participants in our future studies to further confirm our conclusions.

Results of this study showed that PTEN is very likely to be involved in the occurrence and development of RCC in children. Our study provided references for the diagnosis of RCC and development of targeted therapy.

\section{Acknowledgements}

Not applicable.

\section{Funding}

No funding was received.

\section{Availability of data and materials}

All data generated or analyzed during this study are included in this published article. The datasets used and/or analyzed during the current study are available from the corresponding author on reasonable request. 


\section{Authors' contributions}

HL and YT performed RT-qPCR and western blotting. LC extracted total RNA. All authors have read and approved the final manuscript.

\section{Ethics approval and consent to participate}

The study was approved by the Ethics Committee of Zibo Maternal and Child Health Care Hospital (Zibo, China) and informed consents were signed by the parents of the patients.

\section{Patient consent for publication}

Not applicable.

\section{Competing interests}

The authors declare that they have no competing interests.

\section{References}

1. Graves A, Hessamodini H, Wong G and Lim WH: Metastatic renal cell carcinoma: Update on epidemiology, genetics, and therapeutic modalities. Immunotargets Ther 2: 73-90, 2013.

2. Szychot E, Apps J and Pritchard-Jones K: Wilms' tumor: Biology, diagnosis and treatment. Transl Pediatr 3: 12-24, 2014.

3. Silberstein J, Grabowski J, Saltzstein SL and Kane CJ: Renal cell carcinoma in the pediatric population: Results from the California Cancer Registry. Pediatr Blood Cancer 52: 237-241, 2009.

4. González-Sánchez A, Jaraíz-Rodríguez M, Domínguez-Prieto M, Herrero-González S, Medina JM and Tabernero A: Connexin43 recruits PTEN and Csk to inhibit c-Src activity in glioma cells and astrocytes. Oncotarget 7: 49819-49833, 2016.

5. Davis NM, Sokolosky M, Stadelman K, Abrams SL, Libra M, Candido S, Nicoletti F, Polesel J, Maestro R, D'Assoro A, et al: Deregulation of the EGFR/PI3K/PTEN/Akt/mTORC1 pathway in breast cancer: Possibilities for therapeutic intervention. Oncotarget 5: 4603-4650, 2014.

6. Luo X, Liao R, Hanley KL, Zhu HH, Malo KN, Hernandez C, Wei X, Varki NM, Alderson N, Chu C, et al: Dual shp2 and pten deficiencies promote non-alcoholic steatohepatitis and genesis of liver tumor-initiating cells. Cell Rep 17: 2979-2993, 2016.

7. Gao F, Huang W, Zhang Y, Tang S, Zheng L, Ma F, Wang Y, Tang $\mathrm{H}$ and $\mathrm{Li} \mathrm{X}$ : Hes1 promotes cell proliferation and migration by activating Bmi-1 and PTEN/Akt/GSK3 $\beta$ pathway in human colon cancer. Oncotarget 6: 38667-38680, 2015.

8. Kwak MK, Johnson DT, Zhu C, Lee SH, Ye DW, Luong R and Sun Z: Conditional deletion of the Pten gene in the mouse prostate induces prostatic intraepithelial neoplasms at early ages but a slow progression to prostate tumors. PLoS One 8: e53476, 2013.

9. Wang J, Qiu Y, Shi NW, Zhao JN, Wang YC, Jiang H and Qian HB: microRNA-21 mediates the TGF- $\beta 1$-induced migration of keratinocytes via targeting PTEN. Eur Rev Med Pharmacol Sci 20: 3748-3759, 2016.

10. Qi Y, Liu J, Saadat S, Tian X, Han Y, Fong GH, Pandolfi PP, Lee LY and Li S: PTEN induces apoptosis and cavitation via HIF-2-dependent Bnip3 upregulation during epithelial lumen formation. Cell Death Differ 22: 875-884, 2015.
11. Stumpf M and den Hertog J: Differential requirement for pten lipid and protein phosphatase activity during zebrafish embryonic development. PLoS One 11: e0148508, 2016.

12. Stumpf M, Blokzijl-Franke S and den Hertog J: Fine-tuning of pten localization and phosphatase activity is essential for zebrafish angiogenesis. PLoS One 11: e0154771, 2016.

13. Livak KJ and Schmittgen TD: Analysis of relative gene expression data using real-time quantitative PCR and the 2(-Delta Delta C(T)) Method. Methods 225: 402-408, 2001.

14. Ragos V, Fotiades PP, Tsiambas E and Peschos D: PTEN in laryngeal carcinomas. J BUON 21: 1024-1025, 2016.

15. Heymont J, Berenfeld L, Collins J, Kaganovich A, Maynes B, Moulin A, Ratskovskaya I, Poon PP, Johnston GC, Kamenetsky M, et al: TEP1, the yeast homolog of the human tumor suppressor gene PTEN/MMAC1/TEP1, is linked to the phosphatidylinositol pathway and plays a role in the developmental process of sporulation. Proc Natl Acad Sci USA 97: 12672-12677, 2000.

16. Lu XX, Cao LY, Chen X, Xiao J, Zou Y and Chen Q: PTEN inhibits cell proliferation, promotes cell apoptosis, and induces cell cycle arrest via downregulating the PI3K/AKT/hTERT pathway in lung adenocarcinoma a549 cells. BioMed Res Int 2016: 2476842, 2016.

17. Wu KL, Wu CA, Wu CW, Chan SH, Chang AY and Chan JY: Redox-sensitive oxidation and phosphorylation of PTEN contribute to enhanced activation of PI3K/Akt signaling in rostral ventrolateral medulla and neurogenic hypertension in spontaneously hypertensive rats. Antioxid Redox Signal 18: 36-50, 2013.

18. Shojaee S, Chan LN, Buchner M, Cazzaniga V, Cosgun KN, Geng H, Qiu YH, von Minden MD, Ernst T, Hochhaus A, et al: PTEN opposes negative selection and enables oncogenic transformation of pre-B cells. Nat Med 22: 379-387, 2016.

19. Zhang L, Yu Q, He J and Zha X: Study of the PTEN gene expression and FAK phosphorylation in human hepatocarcinoma tissues and cell lines. Mol Cell Biochem 262: 25-33, 2004.

20. Gupta A and Dey CS: PTEN, a widely known negative regulator of insulin/PI3K signaling, positively regulates neuronal insulin resistance. Mol Biol Cell 23: 3882-3898, 2012.

21. Gerisch G, Schroth-Diez B, Müller-Taubenberger A and Ecke M: PIP3 waves and PTEN dynamics in the emergence of cell polarity. Biophys J 103: 1170-1178, 2012.

22. Ebbesen SH, Scaltriti M, Bialucha CU, Morse N, Kastenhuber ER, Wen HY, Dow LE, Baselga J and Lowe SW: Pten loss promotes MAPK pathway dependency in HER2/neu breast carcinomas. Proc Natl Acad Sci USA 113: 3030-3035, 2016.

23. Li J, Yin LL, Su KL, Zhang GF and Wang J: Concomitant depletion of PTEN and p27 and overexpression of cyclin D1 may predict a worse prognosis for patients with post-operative stage II and III colorectal cancer. Oncol Lett 8: 1543-1550, 2014.

24. Qu W, Fu JD, Yang F, Yang GL, Zhang YL, Wang XY, Gu HX, Zhang HY and Wang L: Clinical implications of PTEN andVEGF expression status, as well as microvessel density inesophageal squamous cell carcinoma. Oncol Lett 10: 1409-1415,2015.

This work is licensed under a Creative Commons Attribution-NonCommercial-NoDerivatives 4.0 International (CC BY-NC-ND 4.0) License. 